\title{
DETERMINAÇÂO VOLTAMÉTRICA DO HERBICIDA GLIFOSATO EM ÁGUAS NATURAIS UTILIZANDO ELETRODO DE COBRE
}

\author{
Andresa Fabiana Garcia e Maria do Carmo Rollemberg* \\ Departamento de Química, Universidade Estadual de Maringá, Av. Colombo, 5790, 87020-900 Maringá - PR, Brasil
}

Recebido em 4/8/06; aceito em 15/3/07; publicado na web em 17/7/07

\begin{abstract}
VOLTAMMETRIC DETERMINATION OF GLYPHOSATE IN NATURAL WATERS WITH A COPPER ELECTRODE. The aim of this work was to investigate the copper electrode behavior in the voltammetric determination of glyphosate. The best conditions for this determination are phosphate buffer $0.05 \mathrm{~mol} \mathrm{~L}^{-1}$ and $\mathrm{pH} 7.3$, and the peak potential is observed at $-187 \mathrm{mV}$. LD and LQ values are $59 \mu \mathrm{g} \mathrm{L}^{-1}$ e $196 \mu \mathrm{g} \mathrm{L}^{-1}$, respectively. A water sample was analysed for glyphosate and identical results were obtained by using the analytical curve and the standard addition method. The comparison with a voltammetric method with $\mathrm{Hg}$ electrode, after a reaction with nitrite, showed quite concordant results for the analysis of the surface water sample. Therefore, the proposed method can be applied to direct determinations of the herbicide in waters, decreasing the time of analysis; besides, the method is in agreement with the "green chemistry" concept.
\end{abstract}

Keywords: copper electrode; glyphosate; natural waters.

\section{INTRODUÇÃO}

Uma das maiores causas da contaminação de águas superficiais e subterrâneas atualmente é, sem dúvida, o uso de pesticidas na atividade agrícola. Esta contaminação resulta da ação das águas da chuva e de irrigação que provocam lixiviação, drenagem e escoamento dos pesticidas presentes nas plantações e no solo, os quais atingem cursos d'água ou reservatórios ${ }^{1}$. Em muitos países - inclusive no Brasil - não há programas de monitoramento e/ou controle dos níveis de contaminação em águas, ou a legislação sobre o assunto é pouco clara ou não atualizada ${ }^{2}$.

O Brasil, desde os anos 70, destaca-se como um dos dez maiores consumidores mundiais de pesticidas, mas o único dado relativo à extensão com que são usados no país refere-se às linhas de comercialização, destacando-se a grande utilização de herbicidas, principalmente nas culturas de soja, milho, cana-de-açúcar, café e arroz ${ }^{3-5}$.

$\mathrm{Na}$ molécula do glifosato - $\mathrm{N}$-fosfonometil glicina - (classe dos ácidos fosfônicos) a presença dos grupos funcionais amino, carboxila e fosfonato (Figura 1) explica a capacidade de ligação a íons metálicos formando quelatos 6 . O grupo fosfonato pode formar complexos bastante estáveis com íons metálicos e os grupos funcionais amino e carboxila podem também coordenar-se fortemente com íons metálicos, principalmente dos metais de transição, em soluções de $\mathrm{pH}$ próximo da neutralidade, onde estes grupos encontram-se desprotonados ${ }^{7}$.<smiles>O=C(O)CNCCP(=O)(O)O</smiles>

Figura 1. Estrutura do glifosato

No desenvolvimento de técnicas adequadas à quantificação de pesticidas em águas, a velocidade analítica e o custo da análise são aspectos particularmente importantes. A análise de pesticidas é tradicionalmente realizada recorrendo-se às técnicas cromatográficas, interessantes devido à capacidade de efetuar separações, identifi-

*e-mail: mcerollemberg@uem.br car e quantificar as espécies em uma amostra utilizando diferentes detectores, e aos limites de detecção apropriados ${ }^{8-10}$. Contudo, as técnicas cromatográficas exigem etapas iniciais de derivação ou processos de separação em amostras complexas, utilizam maior quantidade de reagentes e uma instrumentação muitas vezes cara; tudo isso contribui para análises mais demoradas e de maior custo, com geração de maiores quantidade de resíduos químicos9. Também na determinação do glifosato em amostras ambientais a maior parte dos procedimentos envolve métodos cromatográficos cromatografia gasosa ou cromatografia líquida de alta eficiência ${ }^{11}$. Como a molécula do glifosato apresenta elevada polaridade e ausência de cromóforos, a determinação cromatográfica exige etapas preliminares que permitam a detecção/quantificação. Trabalhos recentemente publicados têm utilizado cromatografia líquida de alta eficiência, cromatografia de troca iônica, cromatografia iônica ou cromatografia gasosa; tais procedimentos apresentam boa sensibilidade, mas além de morosos têm custo elevado ${ }^{12-17}$. Uma boa revisão dos métodos utilizados para a determinação de glifosato foi apresentada por Amarante Junior et al. ${ }^{11}$.

As técnicas eletroanalíticas apresentam algumas vantagens em comparação às técnicas cromatográficas na determinação de pesticidas, sendo a principal a possibilidade bastante freqüente da análise direta da amostra, sem uma etapa preliminar de separação ou de pré-tratamento. Embora a aplicação de técnicas eletroanalíticas a amostras complexas também exija, algumas vezes, separações prévias, o processo de separação é simplificado, de menor custo e mais rápido em comparação às técnicas cromatográficas ${ }^{18-20}$. O eletrodo de mercúrio, muito utilizado na determinação de pesticidas em diferentes matrizes, tem uso limitado a intervalos de potenciais negativos, o que exclui seu uso no monitoramento de diversos compostos de interesse ecotoxicológico ${ }^{21}$.

Os eletrodos sólidos, com uma janela de potencial mais positiva, apresentam uma grande aplicabilidade na química analítica. Para a construção de eletrodos sólidos têm sido utilizados materiais como platina, ouro, carbono, ródio, paládio, níquel, ferro, cobre e tungstênio. Os eletrodos metálicos apresentam interesse devido ao mecanismo envolvido nas medidas voltamétricas, que os torna mais seletivos. Como as respostas obtidas são dependentes 
das condições de superfície eletródica, é necessário um pré-tratamento eletroquímico e polimento mecânico para-se obter resultados confiáveis e reprodutíveis; embora a natureza do pré-tratamento seja dependente do tipo de material do eletrodo sólido, polimentos mecânicos e ciclagem de potenciais têm sido utilizados comumente para a ativação da superfície eletródica ${ }^{22}$.

Os grupos funcionais presentes nas moléculas dos pesticidas definem o material do eletrodo de trabalho a ser usado. Sendo assim, por sua capacidade de formar complexos com íons cúpricos, procurou-se estudar a possibilidade de determinar o glifosato utilizando o eletrodo de $\mathrm{Cu}$. Diferentes eletrodos de cobre e formas de medida têm sido aplicados às determinações de aminoácidos, ácidos orgâni$\cos$, proteínas e anions inorgânicos ${ }^{23}$. A necessidade de um pré-tratamento eletroquímico, produzindo uma camada ativa de cobre e, em continuação, uma camada de óxidos/hidróxidos de cobre (camada passivadora) implica que a resposta eletródica resulta da interação do ligante com íons cúpricos presentes nesta camada. A formação da camada passivadora é fortemente dependente das condições da superfície do eletrodo, do meio iônico, do $\mathrm{pH}$ e, também, da concentração de oxigênio. Na presença de espécies capazes de formar complexos com $\mathrm{Cu}^{2+}$, a concentração desse íon e a velocidade da formação do óxido dependem da natureza e da concentração de ligantes na solução. Isto sugere que espécies capazes de formar complexos com os íons cúpricos, tais como o glifosato, podem ser determinadas utilizando eletrodos de $\mathrm{Cu}$, explorando-se o efeito da formação do complexo sobre a intensidade da corrente do pico anódico do $\mathrm{Cu}$. O mecanismo e a intensidade do sinal eletroquímico envolvem a cinética e a termodinâmica da complexação nas condições experimentais ${ }^{23}$. Glass $^{24}$ propôs haver uma interação entre $\mathrm{CuO}$ e glifosato, na interface sólido-líquido, ao observar um aumento da concentração de íons cúpricos na presença do glifosato.

$\mathrm{O}$ glifosato não é eletroativo ao ser usado o eletrodo de $\mathrm{Hg}$. Portanto, a determinação do herbicida exige reações prévias para se obter compostos redutíveis nesse eletrodo ou o uso de outros eletrodos. Estudos anteriores indicaram haver uma forte interação entre os íons $\mathrm{Cu}(\mathrm{II})$ e o glifosato ${ }^{7}$. Procurou-se, então, avaliar o uso do eletrodo de $\mathrm{Cu}$ na determinação direta do glifosato em amostras de águas superficiais, sem a necessidade de reações prévias, e aqui são descritos os estudos referentes à otimização das condições analíticas para esta determinação.

\section{PARTE EXPERIMENTAL}

\section{Equipamentos e reagentes}

As medidas voltamétricas (voltametria cíclica e voltametria de pulso diferencial) foram realizadas utilizando-se um potenciostatogalvanostato PGSTAT-30, com um eletrodo metálico de cobre como eletrodo de trabalho; eletrodos de $\mathrm{Ag}-\mathrm{AgCl}_{\text {sat }}$ e de $\mathrm{Pt}$ foram usados como eletrodos de referência e auxiliar, respectivamente. Nas medidas voltamétricas com eletrodo de gota pendente de $\mathrm{Hg}$ (Metrohm 663 VA) um eletrodo auxiliar de grafite foi utilizado. As medidas de $\mathrm{pH}$ foram realizadas em $\mathrm{pHmetro}$ Quimis (modelo Q-400M, sensibilidade 0,01 ) com eletrodo de vidro combinado.

Eletrólitos-suporte e demais soluções foram preparados a partir de reagentes de grau analítico em água destilada e desionizada de pureza Milli- $\mathrm{Q}^{\circledR}$. O reagente glifosato - [N-(fosfonometil)glicina], 99,9\% - foi cedido pela Monsanto do Brasil e a solução estoque foi preparada por dissolução do reagente em água, resultando na concentração $100 \mathrm{mg} \mathrm{L}^{-1}$. A solução de sulfamato de amônio $(0,10 \mathrm{mg}$ $\left.\mathrm{L}^{-1}\right)$ foi preparada e mantida à temperatura ambiente. A solução de nitrito de sódio $\left(10,0 \mathrm{mg} \mathrm{L}^{-1}\right)$ era preparada imediatamente antes da sua utilização, devido à facilidade de oxidação.
O eletrodo metálico de cobre $(99,9 \%$ de pureza) foi construído introduzindo-se um bastão de $\mathrm{Cu}$ (diâmetro de área exposta de 0,45 $\mathrm{cm})$ em uma seringa plástica $(1,0 \mathrm{~mL})$ para insulina, cuja ponta inferior foi cortada no diâmetro do eletrodo, sendo o bastão metálico fixado com cola de silicone (tubos de vidro não foram utilizados devido à possibilidade de adsorção do glifosato). A cada dia, antes das medidas voltamétricas, o eletrodo de $\mathrm{Cu}$ era polido com lixa d'água 600 e lavado com água destilada e, em seguida, o eletrodo era pré-tratado a fim de se estabilizar sua superfície, realizando-se uma sequiência de trinta ciclos entre $-0,4$ a $0,4 \mathrm{~V}$ (vs $\mathrm{Ag} / \mathrm{AgCl}$ ), no meio otimizado ${ }^{23}$.

\section{Determinação voltamétrica do glifosato utilizando o eletrodo de $\mathrm{Cu}$}

Soluções de diferentes valores de $\mathrm{pH}$ e diferentes composições foram investigadas - nitrato de potássio, $\mathrm{pH}$ 6,83; ácido fosfórico, pH 7,02; hidróxido de sódio, $\mathrm{pH} 12,28$; diidrogênio fosfato de potássio, pH 7,3 e pH 11,5; solução PIPES 0,025 mol L-1, pH 7,3. Todas as soluções, exceto a solução de PIPES, apresentavam concentração de $0,1 \mathrm{~mol} \mathrm{~L}^{-1}$; os valores de $\mathrm{pH}$ foram ajustados com soluções de hidróxido de sódio ou ácido nítrico, com concentração de $0,1 \mathrm{~mol} \mathrm{~L}^{-1}$. Voltametrias cíclicas (VC) foram registradas em cada um destes meios, na faixa de potenciais de $-1,0$ a 1,0 V.

Para as medidas por voltametria de pulso diferencial (VPD) os parâmetros instrumentais foram otimizados no meio anteriormente selecionado. Os voltamogramas foram obtidos usando-se $20,0 \mathrm{~mL}$ da solução do eletrólito na cela voltamétrica e adicionando-se o volume necessário da solução-estoque do glifosato. A excelente reprodutibilidade das correntes medidas para as replicatas indica não haver adsorção do glifosato durante as determinações voltamétricas.

O procedimento adotado para a determinação do glifosato por VPD, utilizando o eletrodo de $\mathrm{Cu}$, consistiu em aplicar uma varredura de potencial na direção positiva, no intervalo $-0,5$ a $0,2 \mathrm{~V}$, sem desoxigenar a solução e observando os seguintes parâmetros: meio,

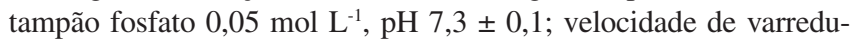
ra, $10 \mathrm{mV} \mathrm{s}^{-1}$; amplitude do pulso de potencial, $150 \mathrm{mV}$; duração do pulso, $150 \mathrm{~ms}$; modulação do pulso, $200 \mathrm{~ms}$. O pico de corrente na presença do glifosato era observado em $-187 \mathrm{mV}$.

\section{Determinação voltamétrica do glifosato utilizando o eletrodo de $\mathbf{H g}$}

O procedimento proposto utilizando o eletrodo de $\mathrm{Cu}$ foi comparado à determinação do glifosato segundo o procedimento desenvolvido por Brönstad e Friestad ${ }^{17,25}$, utilizando a polarografia de pulso diferencial (PPD). O derivado do glifosato foi preparado adicionando-se, em balão volumétrico de $50,0 \mathrm{~mL}$, uma alíquota da solução do herbicida (100 mg L-1), 10,0 mL de $\mathrm{HCl} 5,0 \mathrm{~mol} \mathrm{~L}^{-1}, 0,25 \mathrm{~g}$ de $\mathrm{KBr}$ e 2,5 mL da solução de $\mathrm{NaNO}_{2}$. Após 15 min, tempo para completar a reação, 2,5 $\mathrm{mL}$ da solução de sulfamato de amônio foram adicionados, para consumir o excesso de nitrito, e o volume foi completado com água de pureza Milli-Q ${ }^{\circledR}$. As condições para a determinação do glifosato utilizando o eletrodo de $\mathrm{Hg}$ foram: desoxigenação $\left(\mathrm{N}_{2}\right), 300 \mathrm{~s}$ antes da primeira medida e $30 \mathrm{~s}$ antes das demais, mantendo-se sempre $\mathrm{N}_{2}$ sobre a superficie da solução na cela voltamétrica; velocidade de varredura, $10 \mathrm{mV} \mathrm{s}^{-1}$; amplitude do pulso de potencial, $50 \mathrm{mV}$; duração do pulso, $200 \mathrm{~ms}$; modulação do pulso, $50 \mathrm{~ms}$; potencial inicial, -400 $\mathrm{mV}$ e potencial final, $-1000 \mathrm{mV}$. O potencial do pico de corrente na presença do derivado do glifosato foi observado em $-700 \mathrm{mV}$.

\section{RESULTADOS E DISCUSSÃO}

A partir dos voltamogramas obtidos em diferentes valores de $\mathrm{pH}$ utilizando o eletrodo de $\mathrm{Cu}$, verificou-se que em valores de $\mathrm{pH}$ inferiores a 7 havia oxidação na superfície do eletrodo e dissolução 
do $\mathrm{Cu}^{2+}$ formado (coloração azul na solução), sem portanto ocorrer a formação da camada passivadora. A partir dessa informação realizou-se uma série de experimentos para estudar o comportamento voltamétrico do eletrodo de cobre na presença de glifosato em diferentes eletrólitos suportes, com ajuste de pH. Este estudo mostrou que a resposta para glifosato utilizando o eletrodo de cobre é fortemente dependente da natureza dos íons em solução, sendo a melhor resposta (melhor sensibilidade, maior precisão) observada na presença de tampão fosfato (força iônica 0,1 ) com $\mathrm{pH}$ ajustado a 7,3 $\pm 0,1$. Estas observações estão de acordo com o demonstrado anteriormente, indicando que o eletrodo de cobre responde a ligantes apenas em soluções de $\mathrm{pH}$ acima de 6 , com respostas fortemente influenciadas pelo $\mathrm{pH}$ e pela natureza dos íons da solução, sendo a sensibilidade melhor na presença de íons fosfato ${ }^{26}$.

No meio tampão fosfato $\mathrm{pH}$ 7,3 foi obtido um pico de corrente anódica bem definido por VPD na presença de glifosato. Definido este meio, a resposta para o glifosato utilizando eletrodo de $\mathrm{Cu}$ foi também examinada em soluções com diferentes concentrações do tampão, no intervalo entre $1 \times 10^{-3} \mathrm{~mol} \mathrm{~L}^{-1}$ e $0,5 \mathrm{~mol} \mathrm{~L}^{-1}$. A melhor resposta foi observada para a concentração de fosfato $0,05 \mathrm{~mol} \mathrm{~L}^{-1}$; em soluções mais concentradas ou mais diluídas do eletrólito suporte houve uma redução significativa na sensibilidade e/ou na reprodutibilidade das medidas voltamétricas.

$\mathrm{Na}$ camada passivadora formada a superfície do eletrodo de $\mathrm{Cu}$ foi sugerida a presença de $\mathrm{Cu} / \mathrm{Cu}_{2} \mathrm{O} / \mathrm{CuO} / \mathrm{Cu}(\mathrm{OH})_{2}{ }_{2}^{27}$. Voltamogramas (VC) obtidos em $\mathrm{NaOH} 0,1 \mathrm{~mol} \mathrm{~L}^{-1}$ mostraram dois picos anódicos e dois picos catódicos (Figura 2). O primeiro pico anódico $\left(\mathrm{E}_{\mathrm{p}}=-0,34\right.$ V) é atribuído à formação do óxido cuproso e o segundo pico anódico $\left(\mathrm{E}_{\mathrm{p}}=-0,11 \mathrm{~V}\right)$ é devido à formação da camada passivadora contendo óxido e hidróxido de $\mathrm{Cu}(\mathrm{II})$ e $\mathrm{Cu}(\mathrm{I})^{26}$.

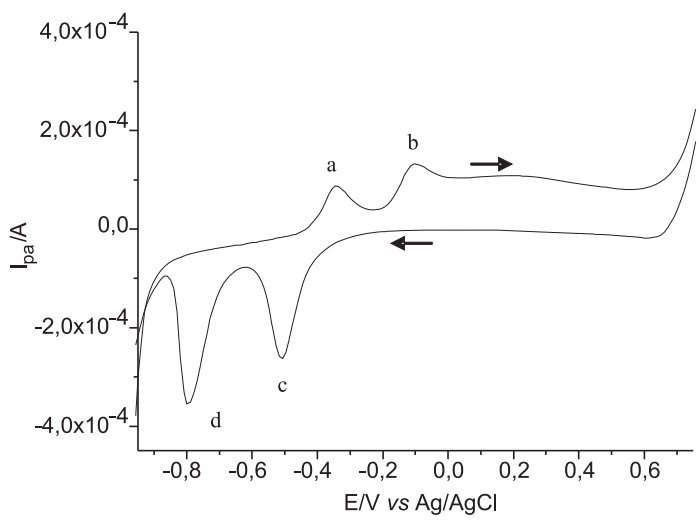

Figura 2. Resposta voltamétrica do eletrodo de cobre em 0,10 mol $\mathrm{L}^{-1} \mathrm{NaOH}$; velocidade de varredura, $100 \mathrm{mV} \mathrm{s}^{-1}$; (a) $\mathrm{Cu}(0) / \mathrm{Cu}(\mathrm{I}):-0,34 \mathrm{~V}$; (b) $\mathrm{Cu}(\mathrm{I}) /$ $\mathrm{Cu}(\mathrm{II}):-0,11 \mathrm{~V} ;$ (c) $\mathrm{Cu}(\mathrm{II}) / \mathrm{Cu}(\mathrm{I}):-0,50 \mathrm{Ve}(\mathrm{d}) \mathrm{Cu}(\mathrm{I}) / \mathrm{Cu}(0):-0,81 \mathrm{~V}$

Nos voltamogramas (VC) registrados no meio tamponado (tampão fosfato, $\mathrm{pH}=7,3$ ) verificou-se a presença de um único pico anódico $\left(\mathrm{E}_{\mathrm{p}}=0,47 \mathrm{~V}\right)$ e dois picos catódicos $\left(\mathrm{E}_{\mathrm{p} 1}=-0,42 \mathrm{~V} ; \mathrm{E}_{\mathrm{p} 2}=-0,65 \mathrm{~V}\right)$ (Figura 3). $\mathrm{O}$ pico anódico indica a oxidação do $\mathrm{Cu}$ a óxido cúprico, não sendo observado o pico relativo à formação do óxido cuproso. A análise do voltamograma parece indicar não haver formação de uma camada passivadora contendo óxido cuproso na varredura positiva e, também, ser a dissolução do óxido cúprico na solução o principal processo. Entretanto, a presença de espécies de $\mathrm{Cu}^{+}$é indicada na varredura negativa, onde são observados dois picos catódicos - redução do $\mathrm{CuO}$ a $\mathrm{Cu}_{2} \mathrm{O}$ e posterior redução do $\mathrm{Cu}_{2} \mathrm{O}$ a cobre metálico, de acodo com as reações representadas a seguir:

$\mathrm{Cu}+2 \mathrm{OH}^{-} \leftrightarrows \mathrm{CuO}+\mathrm{H}_{2} \mathrm{O}+2 \mathrm{e}^{-}$
$2 \mathrm{CuO}+2 \mathrm{e}^{-}+\mathrm{H}_{2} \mathrm{O} \leftrightarrows \mathrm{Cu}_{2} \mathrm{O}+2 \mathrm{OH}^{-}$

$\mathrm{Cu}_{2} \mathrm{O}+\mathrm{H}_{2} \mathrm{O}+2 \mathrm{e}^{-} \leftrightarrows 2 \mathrm{Cu}+2 \mathrm{OH}^{-}$

Isto é possível devido à baixa condutividade do óxido cuproso formado primeiramente (Equação 2), que dificulta a redução do óxido cúprico a óxido cuproso e a redução direta do óxido cúprico a cobre ${ }^{27}$.

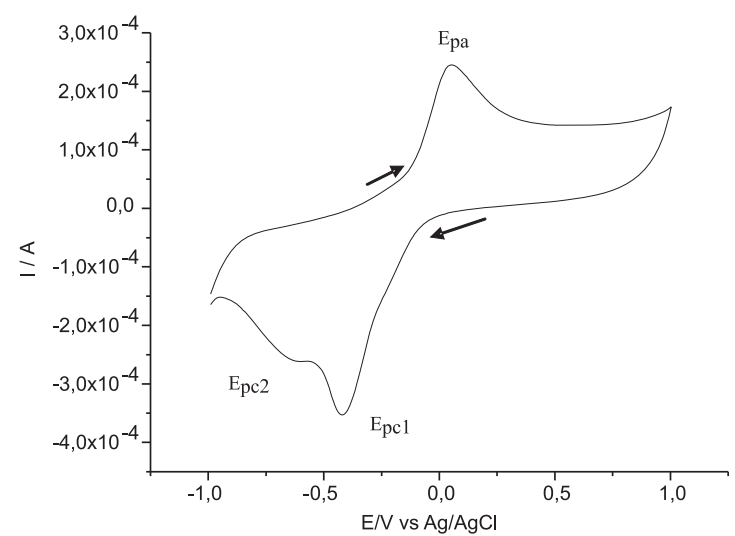

Figura 3. Voltamograma cíclico do glifosato $(336 \mathrm{mg} / \mathrm{L})$ com eletrodo de cobre no meio tamponado (tampão fosfato, $p H \sim 7,3$ ); velocidade de varredura, 100 $m V s^{-1}$; pico anódico: $E_{p}=0,47 \mathrm{~V}$; picos catódicos: $E_{p 1}=-0,42 \mathrm{~V} ; E_{p 2}=-0,65 \mathrm{~V}$

$\mathrm{O}$ processo de formação do complexo $\mathrm{Cu}^{2+}$-glifosato pode ser representado segundo $\mathrm{M}+\mathrm{L} \rightarrow \mathrm{ML}$, onde $\mathrm{L}$ representa o ponto complexante da molécula de glifosato, $\mathrm{M}$ é o íon metálico livre $\left(\mathrm{Cu}^{2+}\right)$ e $\mathrm{ML}$ o complexo com estequiometria 1:1. Este modelo simplificado implica que, se dois ou mais grupos são ligados a um íon metálico, todos esses grupos correspondem a um único ponto de coordenação e, assim, somente o complexo 1:1 é considerado ${ }^{6}$. Em soluções de $\mathrm{pH}$ próximo à neutralidade, a reação do glifosato com íons cúpricos leva à formação de [CuGlif] como espécie predominante, de acordo com a Equação:

$\mathrm{Cu}^{2+}+$ Glif $^{3-} \leftrightarrows[\mathrm{CuGlif}]$

A constante condicional de formação para este complexo 1:1 obtida através de titulação potenciométrica ${ }^{7}$ é $8,32 \times 10^{11}$.

$\mathrm{O}$ efeito da velocidade de varredura no comportamento voltamétrico do eletrodo de $\mathrm{Cu}$ na presença do glifosato foi investigado para valores entre 1 e $50 \mathrm{mV} \mathrm{s}^{-1}$. Os voltamogramas apresentados na Figura 4 indicam uma diminuição na sensibilidade com a diminuição da velocidade de varredura e alargamento dos picos de corrente com o aumento da velocidade; escolheu-se como melhor condição a velocidade de $10 \mathrm{mV} \mathrm{s}^{-1}$. A relação linear entre as correntes de pico e a raiz quadrada da VV indicam que o pico anódico é devido à formação da camada de óxido através da qual a difusão das espécies é responsável por definir o processo total (processo controlado por difusão) ${ }^{27}$.

Os voltamogramas referentes às diferentes concentrações de glifosato obtidos nas condições otimizadas são mostrados na Figura 5.

A curva analítica definida a partir dos voltamogramas apresentados na Figura 5 obedece à relação linear $\mathrm{I}_{\mathrm{p}}(\mu \mathrm{A})=76,7 \mathrm{C}\left(\mathrm{mg} \mathrm{L}^{-1}\right)\left(\mathrm{r}^{2}=\right.$ 0,9891). Os valores calculados para o limite de detecção $(\mathrm{LD}=3 \sigma$ / inclinação) e o limite de quantificação ( $\mathrm{LQ}=10 \sigma /$ inclinação) - respectivamente, 59 e $196 \mu \mathrm{g} \mathrm{L}^{-1}$ - mostram a adequação do procedimento proposto às determinações do glifosato em amostras de águas (sendo $\sigma$ o desvio padrão de 20 medidas sucessivas do branco do procedimento). A repetibilidade do método foi determinada pela análise de cinco replicatas de concentração $0,10 \mathrm{mg} \mathrm{L}^{-1}$; o desvio padrão relativo 

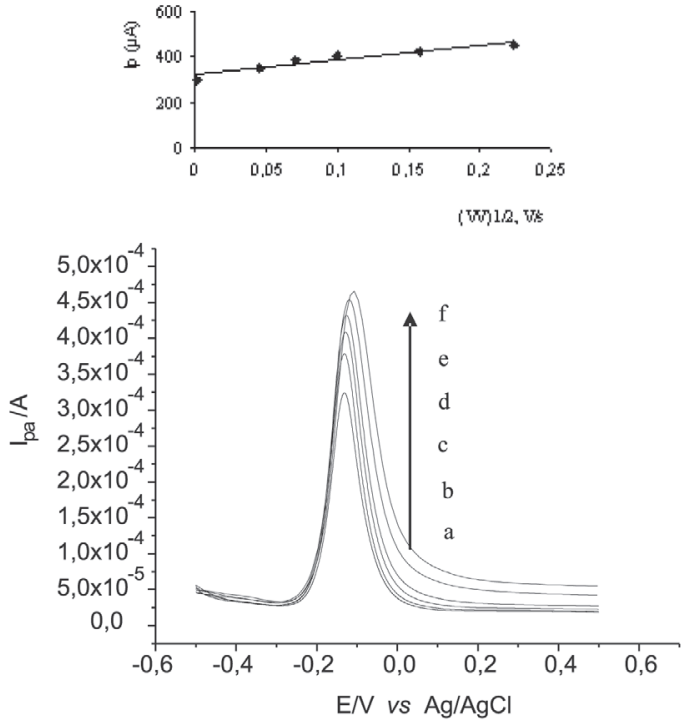

Figura 4. Voltamogramas com eletrodo de Cu na presença de glifosato obtidos em diferentes velocidades de varredura $\left(\mathrm{mV} \mathrm{s}^{-1}\right)$ : (a) 1 ; (b) 2; (c) 5; (d) 10; (e) 25; (f) 50; meio: 0,05 mol $\mathrm{L}^{-1}$ tampão fosfato $\mathrm{pH}$ 7,3 \pm 0,1; concentração de glifosato: $336 \mathrm{mg} \mathrm{L}^{-1}$. Inserção: relação entre as correntes de pico e a velocidade de varredura

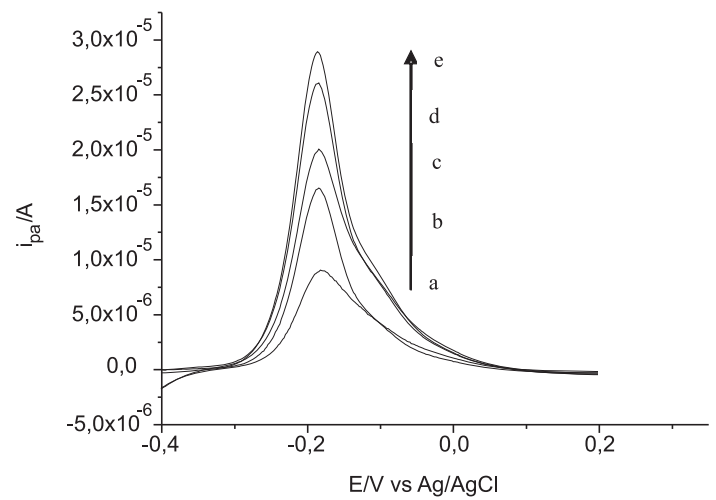

Figura 5. Voltamogramas por voltametria de pulso diferencial utilizando eletrodo de Cu para diversas concentrações de glifosato $\left(m g L^{-1}\right)$ : (a) 0,10; (b) 0,20; (c) 0,30; (d) 0,40; (e) 0,50. Meio: 0,05 mol $\mathrm{L}^{-1}$ tampão fosfato $\mathrm{pH}$ $7,3 \pm 0,1 ; V V=10 \mathrm{mV} \mathrm{s}^{-1}$

calculado foi de $0,06 \%$. Os resultados obtidos mostram que o uso do eletrodo de $\mathrm{Cu}$ na determinação voltamétrica do glifosato por VPD pode ser uma alternativa simples, rápida e adequada à determinação de resíduos do herbicida em amostras ambientais.

Considerando o interesse em técnicas sensíveis para monitorar baixos níveis de glifosato, a aplicabilidade da VPD com eletrodo de $\mathrm{Cu}$ foi investigada para determinar traços do herbicida em amostras de águas de superfície e de abastecimento. Nas amostras de água de abastecimento (água de mina) não foi detectada a presença do glifosato. Os voltamogramas obtidos para uma amostra de água coletada na Represa Taquaruçu, município de Sandovalina, estado de São Paulo, com e sem adição de glifosato são apresentados na Figura 6, onde se observa o aumento do pico anódico com a adição do herbicida. A concentração de glifosato para esta amostra, determinada pela tanto pela curva analítica como pelo método da adição do analito foi $0,18 \mathrm{mg} \mathrm{L}^{-1}$ (Tabela 1). Esta concordância implica não haver interferências significativas da matriz; como, em geral, os níveis de glifosato no ambiente são pequenos, é proposto o uso do método da adição do analito, sem qualquer pré-tratamento da amostra para aumentar a confiabilidade das medidas. $\mathrm{O}$ valor determinado para glifosato na amostra estudada indica a necessidade de um tratamento adequado para consumo humano e mesmo para a exploração pesqueira ou para atividades de lazer $^{2}$; entretanto, esta represa fica situada em uma região agrícola, com intensa pulverização de herbicidas, e a pesca é o meio de subsistência da população ao redor. Uma recuperação satisfatória (média de 107\%) foi obtida na adição das diferentes quantidades de glifosato à amostra estudada, indicando a viabilidade do uso do método proposto no monitoramento ambiental.

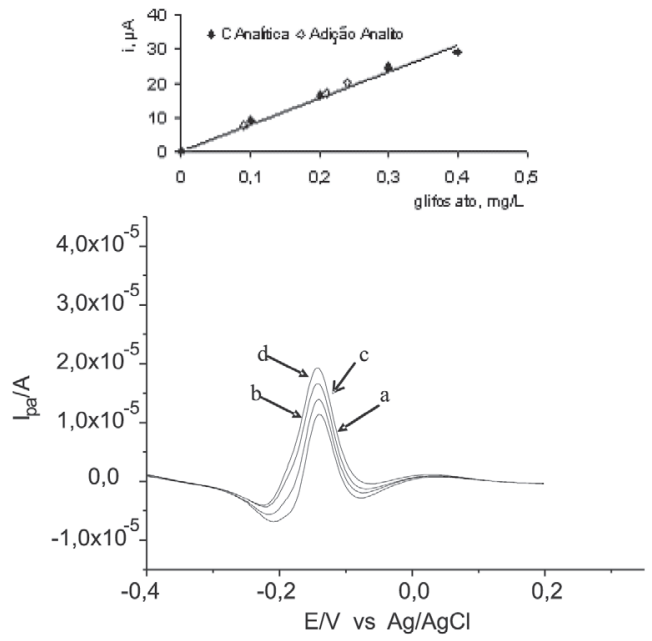

Figura 6. Voltamogramas por voltametria de pulso diferencial utilizando eletrodo de Cu para uma amostra de água natural com e sem adição de glifosato. Concentrações do glifosato adicionado $\left(m g L^{-1}\right)$ : (a) 0 ; (b) 0,24; (c) 0,30 e (d) 0,42. Condições: 0,05 mol $L^{-1}$ tampão fosfato, $p H$ 7,3 $\pm 0,1$. Inserção: curva de recuperação para o glifosato nas condições otimizadas

Para avaliar o método proposto, as amostras de água foram também analisadas segundo o método descrito na literatura utilizando o eletrodo de $\mathrm{Hg}$, após uma reação de derivação com nitrito com formação do grupo N-nitroso, reduzido facilmente no eletrodo de $\operatorname{Hg}^{17,25}$. A concentração da amostra de água natural analisada (Tabela 1) foi $0,21 \mathrm{mg} \mathrm{L}^{-1}$, determinada pelo método da adição do analito (adição de três alíquotas da solução padrão de glifosato a 25,0 $\mathrm{mL}$ da amostra antes da etapa de derivação; processo realizado em triplicata). Este valor é estatisticamente semelhante $(\mathrm{p}=0,05)$ àquele determinado conforme o método desenvolvido utilizando $\mathrm{o}$ eletrodo de $\mathrm{Cu}$ (teste $t)^{28}$. Portanto, o procedimento aqui proposto pode ser aplicado à determinação de glifosato em amostras de água sem necessitar de etapas preliminares à medida voltamétrica.

Tabela 1. Concentração de glifosato em amostra de água de rio $\left(\mathrm{mg} \mathrm{L}^{-1}\right)$ determinada através da voltametria com eletrodo de $\mathrm{Cu}$ e eletrodo de $\mathrm{Hg}$

\begin{tabular}{lcc}
\hline & $\begin{array}{c}\text { Método da Curva } \\
\text { Analítica }\end{array}$ & $\begin{array}{c}\text { Método da Adição } \\
\text { do Analito }\end{array}$ \\
\hline Eletrodo de $\mathrm{Cu}$ & $0,18 \pm 0,01$ & $0,18 \pm 0,01$ \\
Eletrodo de $\mathrm{Hg}$ & $\mathrm{x}$ & $0,21 \pm 0,02$ \\
\hline
\end{tabular}

\section{CONCLUSÃO}

Este trabalho descreve uma alternativa nova para a determinação de glifosato baseada na voltametria com eletrodo de $\mathrm{Cu}$ e sem necessitar de reações prévias. As condições analíticas foram otimizadas visando conseguir uma sensibilidade adequada e os re- 
sultados experimentais demonstraram que o método proposto pode ser utilizado na análise de amostras ambientais aliando rapidez, sensibilidade, simplicidade, baixo custo e obedecendo ao conceito de "método limpo".

\section{REFERÊNCIAS}

1. dos Santos Neto, A. J.; de Siqueira, M. E. P. B.; Quim Nova 2005, $28,747$.

2. Brasil; Resolução CONAMA $n^{\circ} 357$, Ministério do Meio Ambiente: Brasília, 2005; http://www.sindag.com.br, acessada em Julho 2006.

3. Holland, P. T.; Pure Appl. Chem 1996, 62, 1167.

4. Primel, E. G.; Zanella, R.; Kurz, M. H. S.; Gonçalves, F. F.; Machado, S. de O.; Marchezan, E.; Quim. Nova 2005, 28, 605.

5. http://www.cnpma.embrapa.br/herbicidas, acessada em Outubro 2006.

6. Morillo, E.; Maqueda, C.; Bejarano, M.; Madrid, L.; Undabeytia, T.; Chemosphere 1994, 28, 2185.

7. Coutinho, C. F. B.; Mazo, L. H.; Quim. Nova 2005, 28, 1038.

8. Galli, A.; De Souza, D.; Garbellini, G. S.; Coutinho, C. F. B.; Mazo, L. H.; Avaca, L. A.; Machado, S. A. S.; Quim. Nova 2006, 29, 105.

9. Collins, C. H.; Princípios básicos de cromatografia, Ed. Unicamp: Campinas, 1990.

10. Jiang, H.; Adams, C. A.; Koffskey, W.; J. Chromatogr., A 2005, 1064, 219.

11. de Amarante Jr., O. P.; dos Santos, T. C. R.; Brito, N. M.; Ribeiro, M. L.; Quim. Nova 2002, 25, 420.
12. Börjesson, E.; Torstensson, L.; J. Chromatogr., A 2000, 886, 207.

13. Kataoka, H.; Ryn, S.; Sakiyama, N.; Makita, M.; J. Chromatogr., A 1996, 726, 253.

14. Bauere, K. H.; Knepper, T. P.; J. Chromatogr., A 1999, 837, 117.

15. Abdullah, M. P.; Dand, J.; Hong, K. S.; Yew, C. H.; J. Chromatogr., A 1995 , 697, 363.

16. Cowell, J. E.; Kunstman, J. L.; Nord, P. L.; Steinmetz, J. R.; Wilson, G. R.; J. Agric. Food Chem. 1986, 34, 955.

17. Teófilo, R. F.; Reis, E. L.; Reis, C.; Silva, G. A.; Kubota, L. T.; J. Braz. Chem. Soc. 2004, 15, 865.

18. Codognoto, L.; Znin, V. G.; De Souza, D.; Yariwake, J. H.; Machado, S. A. S.; Avaca, L. A.; Microchem J. 2004, 77, 177.

19. Massaropi, M. R. C.; Machado, S. A. S.; J. Braz. Chem. Soc. 2003, 14, 113.

20. Oskan, S. A.; Uslu, B.; Anal. Bioanal. Chem. 2002, 372, 582.

21. Baird, C.; Environmental Chemistry, $2^{\text {nd }}$ ed., Freeman: Houndmils, 2000.

22. Wang, J.; Stripping Analysis: Principles, Instrumentation and Applications, VCH Publishers: Deerfield Beach, 1985.

23. Štulík, K.; Pacáková, V.; Le, K.; Hennissen, B.; Talanta 1988, 35, 455.

24. Glass, R. L.; J. Agric. Food. Chem. 1984, 32, 1249.

25. Brönstad, J. O.; Friestad, H. O.; Analyst 1976, 101, 820.

26. Kok, W. Th.; Hanekamp, H. B.; Bos, P.; Frei, R. W.; Anal. Chim. Acta 1982, 142,31 .

27. Lorimer, J. P.; Mason, T. J.; Plattes, M.; Walton, D. J.; J. Electroanal. Chem. 2004, 568, 379.

28. Simões Gonçalves, M. L. S.; Métodos Instrumentais para Análise de Soluções, $4^{\mathrm{a}}$ ed., Fundação Calouste Gulbenkian: Lisboa, 2001. 